\title{
STUDY OF AUTOMATIC TRAFFIC SIGNAL SYSTEM FOR CHANDIGARH
}

\author{
${ }^{1}$ Tripti Singh Sarkar, ${ }^{2}$ Surya Prakash Sharma \\ ${ }^{1} P G$ Student, Suyash Institute of Technology, Gorakhpur, \\ 2 Assistant Professor, Buddha Institute of Technology, Gorakhpur,
}

\begin{abstract}
The increasing number of vehicles on our road intersections has given rise to the problems like road accidents, congestions, conflicts and bottlenecks. These problems can now only be solved by providing an efficient traffic control at intersections and that can be achieved by provision of automated volume-based traffic signal system at intersections for continuous and efficient movement of vehicles through the intersections

Chandigarh - the city beautiful - though a modern and well-planned city, is also facing the same traffic problems. Here, the present traffic signals are based on the static feed of time without considering the actual available traffic. This leads to a situation where vehicles wait unnecessarily in one of the lanes while the traffic flow is not up to the considerable amount in the other lane. This paper provides the feasibility of replacing existing traffic signals with a system to monitor the traffic flow automatically in traffic signals where sensors are fixed in which the time feed is made dynamic and automatic by processing the live detections.

The paper deals with the feasibility of provision of inductive loop detection-based traffic signals in place of existing Pretimed traffic signals by comparing their performance, suitability and economics.
\end{abstract}

KEYWORDS: Traffic Control, Inductive loop Detector, PCU, Automatic Traffic Control, Intersection, Traffic Field Studies.

\section{INTRODUCTION}

Intersections are important part of a road section. When provided without any proper traffic control measures, they end up with congestion and Bottlenecks. So, to prevent this issue, these should be designed on the aim of decreasing It has been observed during this study that many intersections in Chandigarh have become inadequate to handle the present-day traffic causing congestion ${ }^{[2]}$, delays, bottlenecks and accidents particularly during the peak hours as the traffic control system installed on these intersections are Pretimed.

The efficiency of traffic control atthe intersection can now only be improved by the provision of automatic traffic signal system which works on real-time detections and eliminates the wastage of green time allotted to a phase.

Madhya Marg is one of the most important roads in Chandigarh as it connects P.G.I. to Panchkula ${ }^{[1]}$. In addition to this, it also provides access to many educational institutes, shopping centers, restaurants, corporate offices, grain market etc. It is also the only route for the traffic moving towards Shimla \& Kalka. So due o the above constraints, its consideration for research works has been arosen which deals with the Placement of automatic traffic signals at the intersections to enable the efficient traffic control of traffic and also the faster clearing off the traffic from the intersection.

Along the Madhya Marg, starting from PGI there are11 intersections ${ }^{[4]}$ up to Housing Board Chowk among them 5 have been converted into signalized intersections and 6 are converted into rotaries. The signalized intersections are based on fixed time traffic signal system. In this paper, existing traffic conditions at one of the major intersections of Madhya Marg i.e. Transport Chowk was examined and traffic volumes and speed data were taken accordingly. The signal timings for pretimed traffic signals were redesigned by making use of Webster's/ IRC method and also automatic traffic signals were designed and these both were compared for in terms of their performance and economy. 


\section{LITERATURE REVIEW}

Vidhya \& Banu ${ }^{[9]}$ (2014) designed a project to develop a density based dynamic traffic signal system. The project consisted processing of image captured in the traffic signal and then it was converted to grayscale image and after that to calculate the number of vehicles contours were drawn to have its threshold. Calculation of number of vehicles gave the density which was further used for allocating green time to the traffic on the approach lane by using the Raspberry pi as a microcontroller.

Karthick et al ${ }^{[10]}$ (2012) proposed a system to analyze the live video camera recordings to handle the traffic automatically by allotting green time to the traffic by calculating the number of vehicles which gives the traffic density which acted as a input for the algorithm which was in place for allocating optimal time for the vehicles to pass the intersection.

Khiang Tan et al ${ }^{[12]}$ (1996) developed a graphical simulation windows software for the design and implementation of an automatic traffic lights controller by making use of fuzzy logic technology and also compared the designed software results with conventional lights controller in which the designed one was found to be superior in terms of performance and cost. Rekha \& Karthika ${ }^{15}(2013)$ presented a combination of inductive loop sensors and fuzzy logic technology in which inductive loop sensors were responsible for real-time traffic data and fuzzy logic technology was responsible for the allotment of green time to the traffic to clear off the intersection efficiently. This method was proved to be very effective in handling the traffic.

Rashid Hussain et al ${ }^{[16]}$ (2013) proposed the concept of Wireless sensor network technology have the real- time traffic data at an intersection and then to allocate the timings to the traffic to clear off the intersection. This method was proceed to be efficient as it didn't required any built in system in vehicles for its working.

Shilpa et al ${ }^{[19]}$ (2009) worked on a new technique "Intelligent traffic light controller" which was made by making use of GSM services as it included providing the information regarding traffic flow to users by sending SMSs in addition to the sensors provided on the intersection to allocate the timings to clear off the intersection. This system was compared with fixed traffic signals and found to be more efficient.

\section{INSTRUMENTS \& METHODS}

\section{Methodology}

In present study, firstly, Traffic field studies is used to have the traffic volume and speed data of the Transport Chowk Intersection which are used as input for the redesign of pretimed traffic signals ${ }^{[8]}$ by Webster's and IRC method and for the design of automatic traffic signals.

The figure 1 shows the existing layout of Transport Chowk Intersection and all the dimensions are in meters.

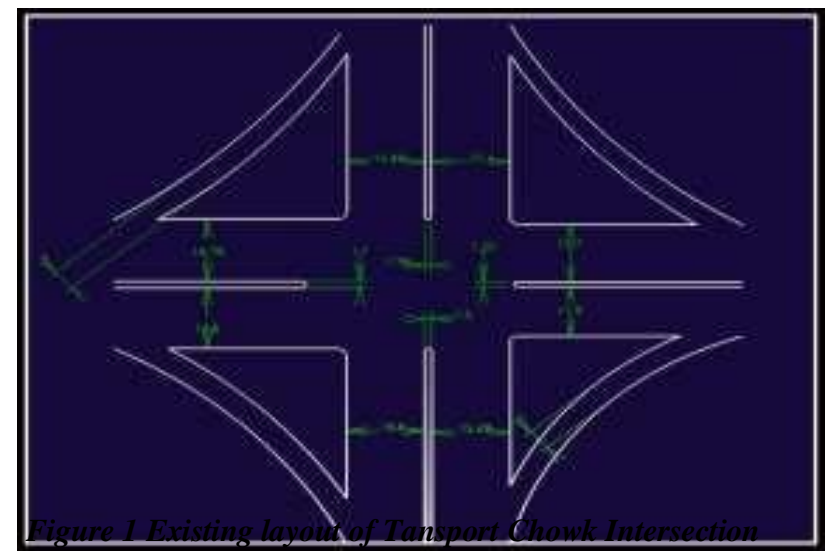




\section{Instruments/Gadgets Used \\ 1. Sony Handy Cam \\ 2. Smartphones \\ 3. Power Bank \\ 4. Radar Gun}

Methods Used:

1. Traffic Volume Study

2. Traffic Speed Studies

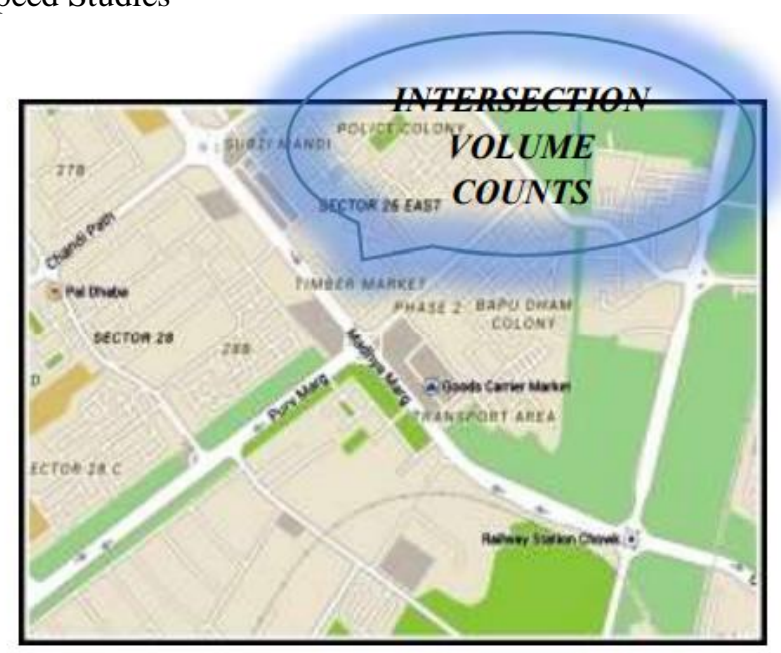

Figure 2 Location of Traffic Volume Counts

A video of the traffic at Transport Chowk shown in figure 2 was recorded for the duration of continuous 12 hours i.e. 8:00 AM to 8:00 PM in order to have the entire day traffic data ${ }^{[17]}$ and also to identify the peak and off peak hours for the traffic flow.

Traffic speed studies was done on the mid-block section each approach lane of the junction by use of Radar gun by taking $50-100$ observations ${ }^{[11]}$ in the input data.the variation in speed of traffic at all the four legs is shown in figure 3,4,5 and 6.

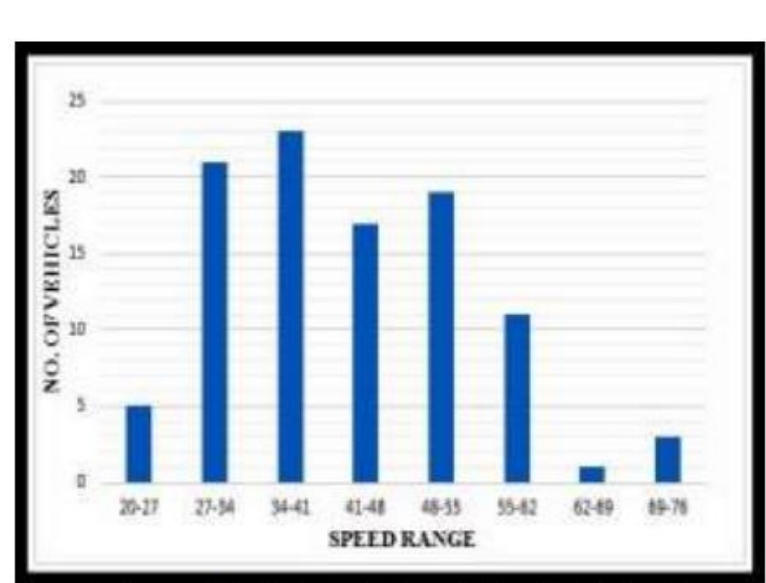

Figure 3 Variation in Speed of traffic in leg 1

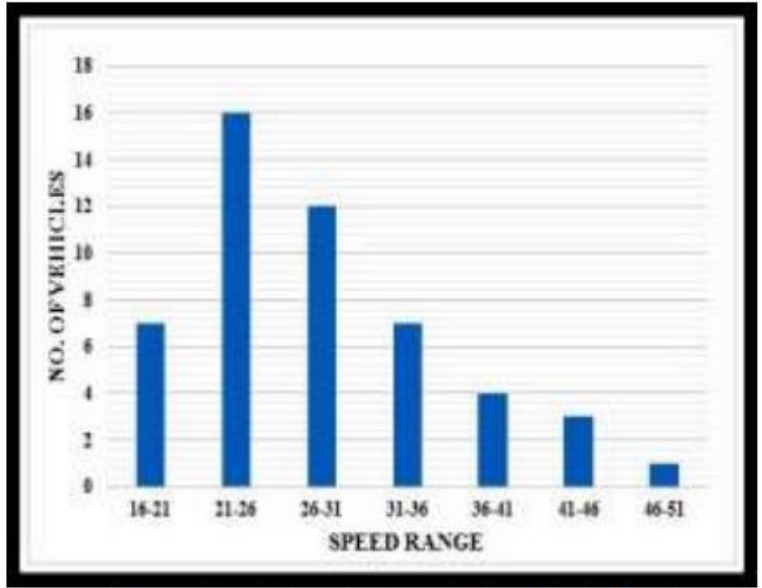

Figure 4 Variation in Speed of traffic in leg 2 


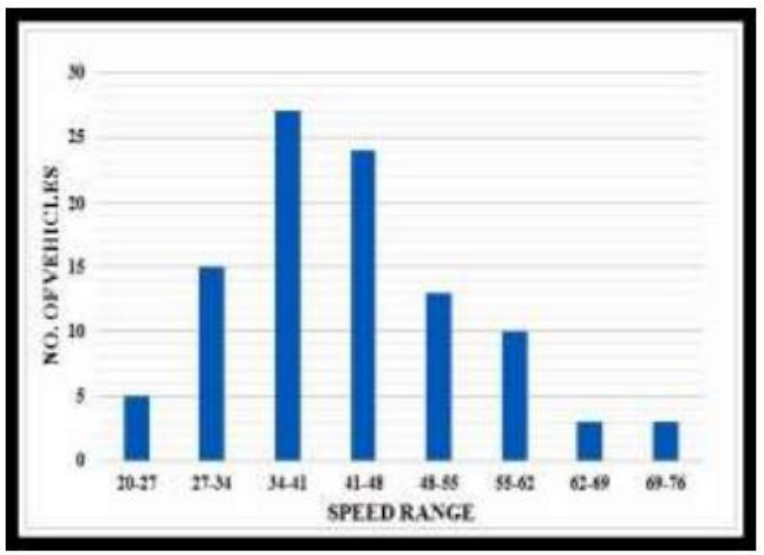

Figure 5 Variation in Speed of traffic in leg 3

Table 1 shows the percentile speeds of all the approach lanes of Transport Chowk Intersection which are found out from cumulative frequency distribution curves made from the data collected by making use of the radar gun. ${ }^{[1]}$

From the traffic volume studies, videos are counted for 15-minute interval ${ }^{[17]}$ for each 4 hours i.e., 8:00 -12:00, 12:00 - 16:00 and 16:00 - 20:00 Hrs. on vlc media player on laptop by slowing the playback speed in order to find out the peak hour

flow by converting the vehicles into the PCU i.e., Passenger Car Unit by making use of the PCU Factors ${ }^{[5]}$ given in table 2

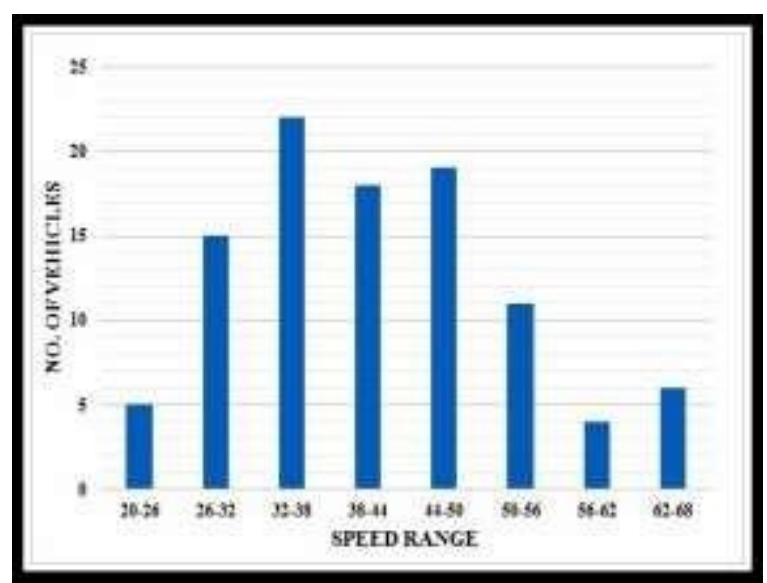

Figure 6 Variation in Speed of traffic in leg 4 
Table 1. Perecentile Speeds

\begin{tabular}{|c|c|c|c|c|}
\hline \multirow{2}{*}{ Approach Lane } & \multicolumn{4}{|c|}{$\begin{array}{c}\text { Percentile Speed } \\
\text { (KM/H) }\end{array}$} \\
\cline { 2 - 5 } & $\mathbf{9 8}^{\text {th }}$ & $\mathbf{8 5}^{\text {th }}$ & $\mathbf{5 0}^{\text {th }}$ & $\mathbf{1 5}^{\text {th }}$ \\
\hline From PGI & 68 & 52 & 38 & 27 \\
\hline $\begin{array}{c}\text { From Grain } \\
\text { Market }\end{array}$ & 44 & 34 & 24 & 19 \\
\hline $\begin{array}{c}\text { From Housing } \\
\text { Board }\end{array}$ & 68 & 52 & 38 & 28 \\
\hline $\begin{array}{c}\text { From Industrial } \\
\text { Area }\end{array}$ & 63 & 50 & 38 & 27 \\
\hline
\end{tabular}

Table 2. PCU Factors used for traffic signal design

\begin{tabular}{|l|l|}
\hline Vehicle & PCU Factor \\
\hline Car & 1 \\
\hline $\mathbf{2 W}$ & 0.5 \\
\hline $\mathbf{3 W}$ & 1 \\
\hline Bus/Truck & 3 \\
\hline Cycle & 0.5 \\
\hline Rickshaw & 1.5 \\
\hline LCV & 1.5 \\
\hline Horse Drawn & 4 \\
\hline Tractors & 4.5 \\
\hline
\end{tabular}

From the figure 7, the peak hour was found to be between 9.15-10.15 hours as 7046 PCU/hr. Figure 8 shows the composition of traffic in the entire day and gives the idea of the traffic being heterogeneous.

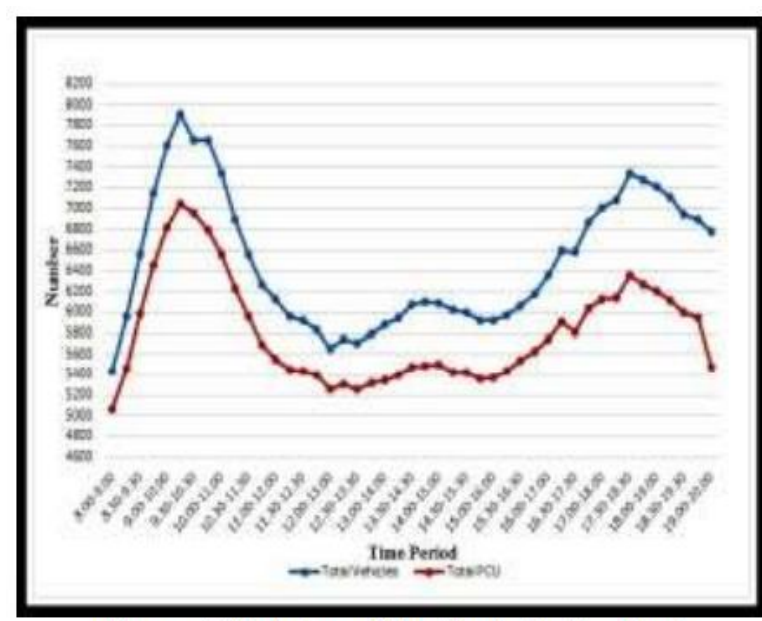

Figure 7 Variation of Traffic in Entire Day4

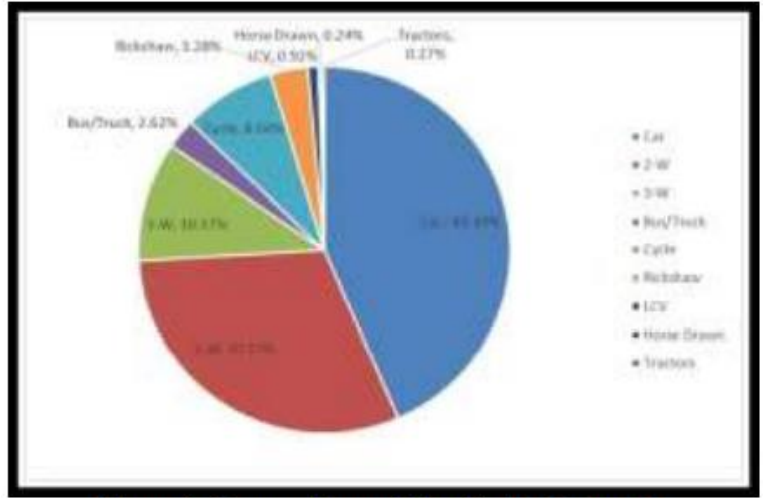

Figure 8 Composition of Traffic in Entire Day

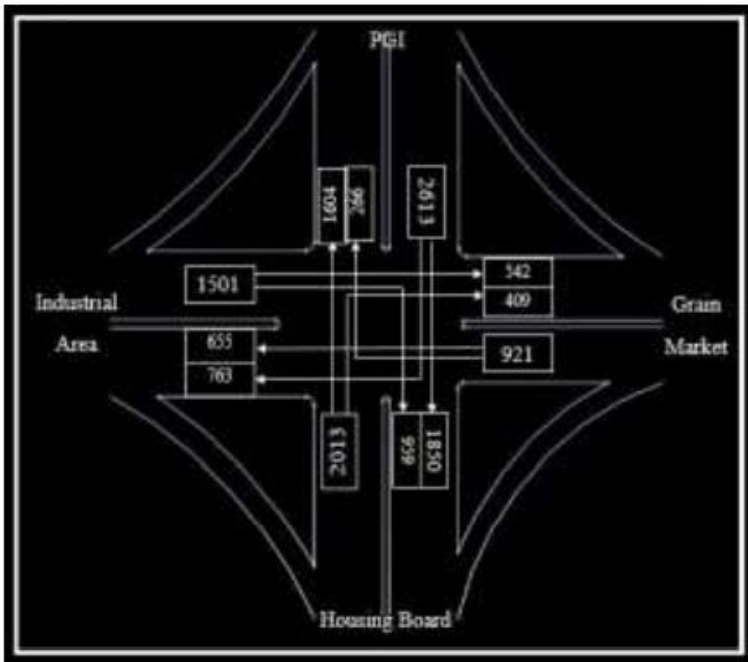

Figure 9 Traffic Flow Diagram for the Peak Hour Flow 
Figure 9 shows the turning movements of traffic during peak hour and all the figures are in PCU i.e. Passenger Car Unit. The pretimed traffic signals and automatic traffic signals were designed for this peak hour flow. by making use of webster's method cycle time is designed.

\section{Pretimed Traffic Signals}

A four-phase signal system was designed for the intersection by making use of Webster's method for signal design and IRC method for the minimum time for pedestrian crossing. [6]

As the slip roads have already been provided at the intersection left turns are not included in the signal design and only right turning movements and straight traffic is included.[11]

The Transport Chowk is shown in figure 10 and four phases taken into design consideration are:[8]

Phase 1: Straight \& Right movement for lane 1

Phase 2: Straight \& Right movement for lane 3

Phase 3: Straight \& Right movement for lane 4

Phase 4: Straight \& Right movement for lane 2

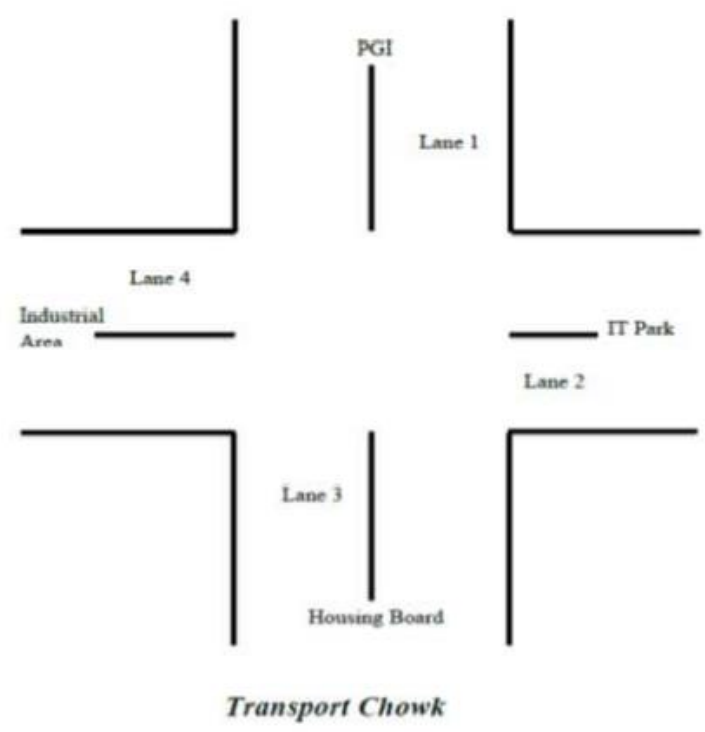

Figure 10 Study Area

Pretimed signals are designed by making use of the webster's method of signal design and IRC method. Webster's method gives the optimum cycle length whereas the IRC method gives the minimum green time on the basis of time taken by pedestrians to cross the approach lanes[15].

$$
\mathrm{Co}=\frac{1.5 \mathrm{~L}+5}{1-\mathrm{y}}
$$

Where, Co is optimum cycle time, $\tilde{\mathrm{L}}$ is lost time and $\mathrm{y}=$ sum of maximum present flow to saturation flow ratios of all the phases.

\section{Automatic Traffic Signals}

These are designed by on the basis of their working principle i.e. minimum green time, unit extension or passage time, maximum green time. The phases are same as taken in the pretimed signal design. Operating principle of these traffic signals include firstly allotment of green time for a minimum time which is independent of any detections of vehicles and will occur in each cycle. The minimum green may be taken according to the IRC recommendations or on the number of vehicles to be passed or can also be fixed by fixing the location of 
detector from stop line [14].The automatic signals designed in this study are based on point detection. So minimum green time is given by:

$$
\mathrm{G}_{\min }=\mathrm{t}_{\mathrm{L}}+[\mathrm{h} \times \text { integer }(\mathrm{d} / \mathrm{x})]
$$

Where, $\mathrm{Gmin}=$ minimum green time in second, $\mathrm{tL}=$ assumed start-up lost time $=4 \mathrm{sec}, \mathrm{h}=$ assumed saturation headway $=2 \mathrm{sec}, \mathrm{d}=$ distance between detector \& stop line in $\mathrm{m}$ and $\mathrm{x}=$ assumed distance between stored vehicles $=6 \mathrm{~m}$. Secondly, Unit Extension time is given to the phase if any vehicle is detected by the detector.it is also know as passage time i.e. time required by the vehicle to cross the distance between detector and stop line and is given by:

$$
\mathrm{P}=(\mathrm{d} / \mathrm{S})
$$

Where, $\mathrm{P}=$ passage time, sec, $\mathrm{d}=$ distance from detector to stop line, meter and $\mathrm{S}=$ approach speed of vehicles, $\mathrm{m} / \mathrm{s}$. (15th Percentile speed) Thirdly, the minimum green time is extended to the maximum green time which is found out by increasing the cycle length obtained in pretimed signal operation by 150 percent. Figure 11 shows the operating principle of an automatic traffic signal.

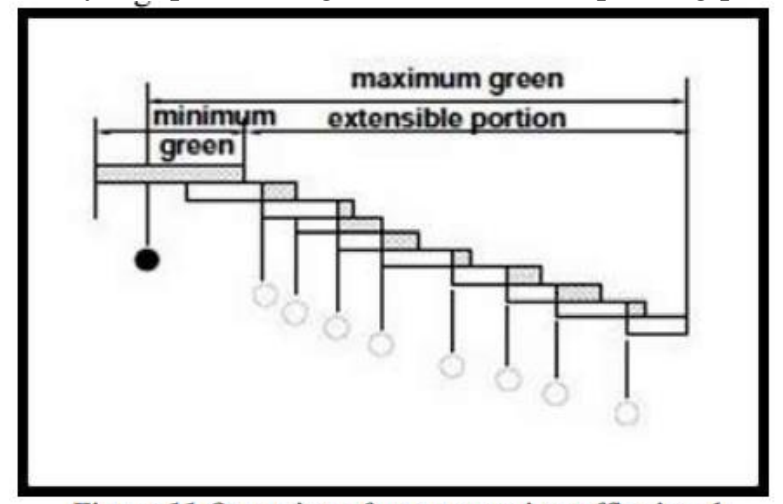

Figure 11 Operation of an automatic traffic signal

The inductive loop detectors could be used to have the real-time traffic data or to detect the vehicles in case of automatic traffic signals.

\section{Future Traffic Prediction}

Also the peak hour so found is then further used to predict the growth of traffic in next 10 years. The formula applied for calculations of the projected traffic volume for the next ten years is as [7]

$\mathbf{A}=\mathbf{P}(\mathbf{1}+\mathbf{r}) \mathrm{n}$

Where, $\mathrm{A}$ is the projected traffic volume, $\mathrm{P}$ is the volume count of the available year or current year, $\mathrm{r}$ is the rate of growth of traffic per year usually taken as 0.075 [7] and $\mathrm{n}$ is number of years. The peak hour traffic is generally 8- $10 \%$ of the Average Daily Traffic (ADT), hence from the above table, by assuming $9 \%$ the ADT may be taken as 78300 PCU/Day.

\section{Capacity of Intersection}

By making use of the formula given below the capacity of a lane for the both pretimed and automatic traffic signals can be computed as, [3]

$\mathrm{c}_{\mathrm{i}}=\mathrm{s}_{\mathrm{i}} \times \frac{\mathrm{g}_{\mathrm{i}}}{\mathrm{C}}$

Where ci is the capacity of lane in vehicle per hour, si is the saturation flow rate in vehicle per hour per lane, gi is the effective green time allotted to the lane in seconds and $\mathrm{C}$ is the cycle time in seconds. By combining the capacity of all the approach lanes, we get the capacity of intersection. 


\section{Level of Service}

By making use of the capacity of each approach lane intersection level of service for each lane is calculated by dividing the present traffic volume by the capacity and LOS can be read from the figure 12. [11]

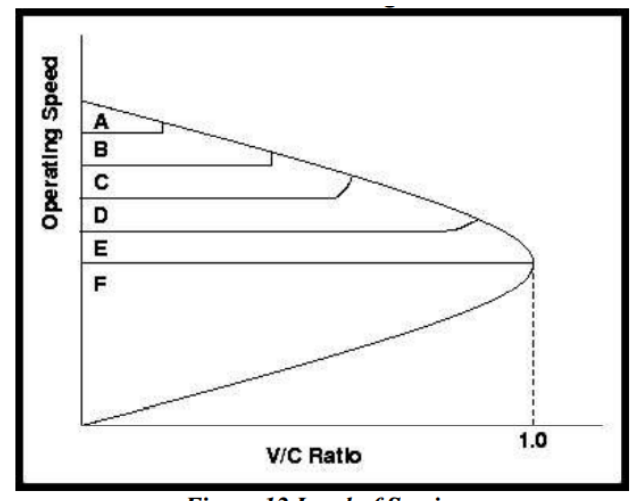

Figure 12 Level of Service

\section{RESULTS AND DISCUSSION}

Figure 13 shows the phase diagram for the pretimed signal operation which gives the designed cycle length and allotted green time for different phases and amber times for the same.

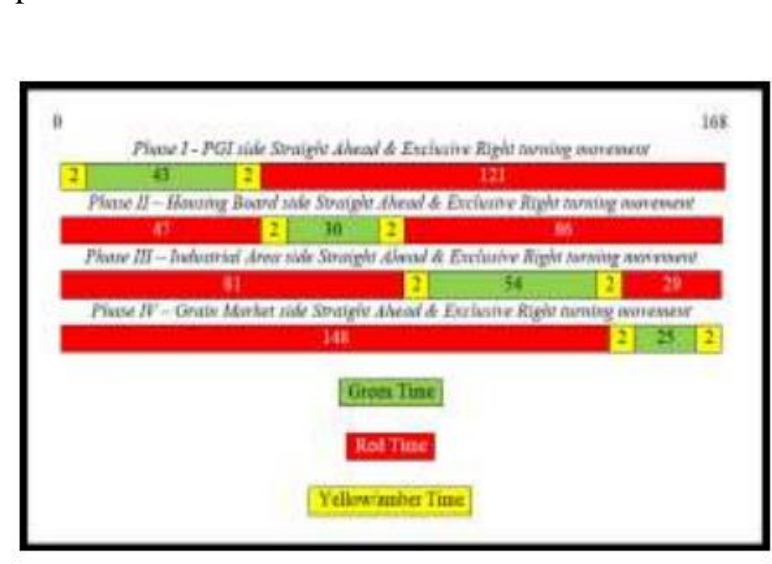

Figure 13 Phase diagram for Pretimed traffic signals

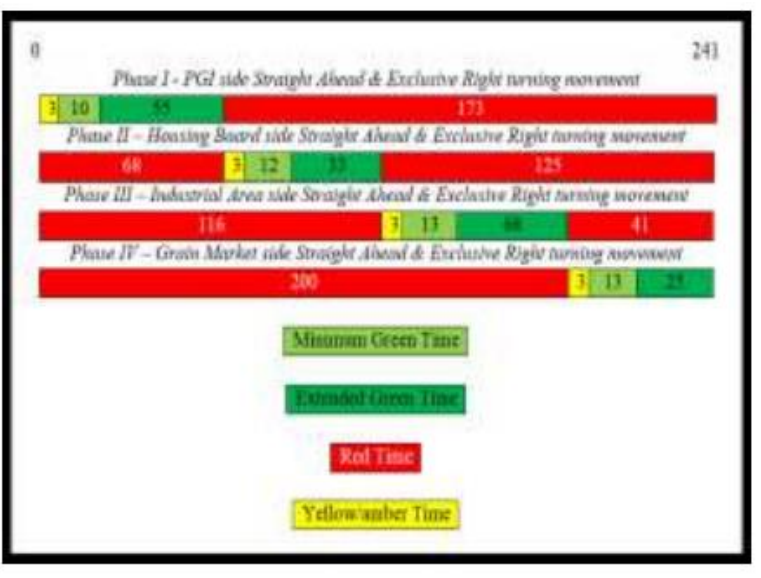

Figure 14 Phase diagram for Automatic traffic signals

Figure 14 shows the phase diagram for automatic traffic signals and gives the designed cycle length, minimum green time, maximum green time and amber time of all the phases. All the figures are in seconds. 


Table 3. Comparison of Pretimed and Automatic
Traffic Signals
\begin{tabular}{|l|l|l|l|l|}
\hline $\begin{array}{l}\text { Approach } \\
\text { Lane }\end{array}$ & $\begin{array}{l}\text { Pretimed } \\
\text { Signals }\end{array}$ & $\begin{array}{l}\text { Automatic } \\
\text { Signals }\end{array}$ \\
\cline { 2 - 5 } & $\begin{array}{l}\text { Capacity } \\
\text { PCU/hr }\end{array}$ & LOS & $\begin{array}{l}\text { Capacity } \\
\text { PCU/hr }\end{array}$ & LOS \\
\hline From PGI & 2516 & F & 2651 & E \\
\hline $\begin{array}{l}\text { From } \\
\text { Grain } \\
\text { Market }\end{array}$ & 1116 & E & 1182 & D \\
\hline $\begin{array}{l}\text { From } \\
\text { Housing } \\
\text { Board }\end{array}$ & 1755 & F & 1835 & F \\
\hline $\begin{array}{l}\text { From } \\
\text { Industrial } \\
\text { Area }\end{array}$ & 2993 & B & 3129 & B \\
\hline
\end{tabular}

From the above table 3 it can be seen that the capacity is increased in case of automatic traffic signals and Level of Service is also improved, so as far as capacity part is concerned Automatic traffic signals are better than pretimed traffic signals. As far as waiting time is concerned, as automatic signals work on real-time detections by making use of inductive loop detector technology, the waiting time of the vehicles is lesser than that of in case of pretimed traffic signals. Wasted time is almost negligible in case of Automatic traffic signals as the real-time detection of absent traffic will give the green time to the next phase. In case of pretimed traffic signals timings are fixed and lot of time is wasted when there is no traffic on the lane to which green time is allotted. It was seen that automatic traffic signals are expensive than the pretimed traffic signals by a margin of Rs. 2,10,000 but as these give more performance than the pretimed traffic signals in terms of capacity and time saving these can be installed at the Transport Chowk intersection.[18]

\section{CONCLUSION}

It can be concluded that the by replacing the pretimed traffic signals with the automatic traffic signals, capacity is being increased and LOS is also being improved. Detector technology to be used for the detection of vehicles is Inductive loop which is commonly used and simple to install, operate and maintain. When pretimed traffic signals fail to clear off the intersection traffic police must clear off the intersection by turning off the traffic signals and handling the traffic manually on their own. This problem can be solved by placing automatic traffic signals. As automatic signals are saving the wasted time and increasing the capacity the expensive part can be tolerated and hence, they can be provided at Intersection. After 3 years Webster's method of signal design fails to design the signal for the traffic as the value of $Y$ comes greater than 1. So at this situation automatic traffic signals comes into play as they will be detecting real-time traffic and assigning the green time for the approach lanes to clear off the traffic.

\section{ACKNOWLEDGEMENTS}

We are grateful to the project coordinator, HOD and staff of mechanical engineering department, PEC University of Technology, Chandigarh for giving us the opportunity to work on this project and for guiding us throughout our research work. We are also thankful to SSP Traffic Police Department, Chandigarh for providing the permissions and facilities necessary for completion of our research work. Special thanks to our family and friends for supporting us throughout our work. 


\section{REFERENCES}

[1] Chandigarh Administration, "Chandigarh Master Plan 2031".

[2] Chandigarh traffic Police. "Black Book 2014".

[3] Dr. Bhargab Mehta, "Introduction to Transportation Engineering", Department of Civil Engineering, IIT Kharagpur.

[4] Finance Secretary (Chandigarh Administration), "City Plan Development Plan" Chandigarh, JNNURM, Govt. of India.

[5] Indian Road Congress "IRC SP 41, Guidelines on design of At-grade intersections in rural and urban areas" IRC New Delhi.

[6] Indian Road Congress "IRC -93:1985, Guidelines on design on installation of road traffic signals." IRC New Delhi.

[7] Indian Road Congress "IRC -108:1996, Guidelines for Traffic prediction on Rural highways" IRC New Delhi.

[8] Pardeep K. Gupta and Ishant Sharma,April- June 2015, "Study of Traffic Flow in an Entire Day at a Congested Intersection of Chandigarh", Journal of Civil Engineering and Environmental Technology ISSN : 2349- 8404,Volume 2, Number 12, pp. 70-73.

[9] K. Vidhya and A. Bazila Banu, March 2014, "Density Based Traffic Signal System”, International Journal of Innovative Research in Science, Engineering and Technology, Volume 3, Special Issue 3, pp. 2218-2222.

[10] Karthick S, Deeban B and S. Abirami, March 2012, "Automated Traffic Signal Prediction from Surveillance Videos", International Journal of Computer Applications, Volume 42, issue 1, pp. 41-45.

[11] Khanna, Justo. "Highway Engineering", Nem Chand \& bros. Roorkee, 2005.

[12] Kok Khiang Tan, Marzuki Khalid and Rubiyah Yusof, December 1996, "Intelligent Traffic lights control by fuzzy logic”,Malaysian Journal of Computer Science, volume - 9, Issue 2, pp. 29-35.

[13] N.P.T.E.L. (nptel.ac.in/courses/105101008) "Design principles of traffic Signal" Chapter 34, Traffic Engg. Management, April 02, 2012.

[14] Tom V. Mathew, "Transportation Engineering - I", Transportation Systems Engineering, Civil Engineering Department, India Institute of Technology Bombay, 2006.

[15] R. Rekha and R. Karthika, June 2013, "Fuzzy Based Traffic Congestion Detection \& Pattern Analysis Using Inductive loop Sensor", International Journal of Scientific \& Engineering Research ISSN:2229-5518,, Volume 4, Issue 6, pp. 1149-1152

[16] Rashid Hussain, Sandhya Sharma,Vinita Sharma and Sandhya Sharma, July 2013, "WSN Applications: Automated Intelligent Traffic Control System Using Sensors", International Journal of Soft Computing and Engineering (IJSCE) ISSN: 2231-2307, Volume 3, Issue 3, pp. 77-81.

[17] Robertson, H. D. 1994. Volume Studies. In Manual of Transportation Engineering Studies, ed. H.D. Robertson, J. E. Hummer, and D. C. Nelson. Englewood Cliffs, N.J.: Prentice Hall, Inc., pp. 6-31.

[18] RR Electronics (an RR Group Co), SCO 181/22, Industrial Area Phase I, Chandigarh

[19] Shilpa S. Chavan, Dr. R. S. Deshpande and J.G. Rana, 2009, "Design of Intelligent Traffic Light Controller using embedded system, Proceedings of the Second International Conference on Emerging Trends in Engineering and Technology, pp. 1086-1091 